\title{
ANALISIS KINERJA PMS REL 2 BAY TRAFO 6 MENGGUNAKAN THERMOVISION METHODE DI GARDU INDUK SUNYARAGI
}

\author{
Agus Siswanto $^{1)}$, Reza Alfian ${ }^{2)}$, Erfan Subyanta ${ }^{3)}$ \\ 1,2,3) Prodi Teknik Elektro-FT, Universitas 17 Agustus 1945 Cirebon \\ Kampus Jl Perjuangan 17 Cirebon \\ e-mail : asiswanto.untagcrb@gmail.com, ralfian854@gmail.com,
}

\begin{abstract}
In an effort to provide reliable and efficient electrical energy, substations have an important role in regulating the demand for electric power loads and as a center for securing electrical power system components in a certain area. Frequent disturbances become a benchmark for an electric power system whether or not it is good or not in an effort to provide reliable and efficient energy. One of the maintenance measures is temperature measurement using thermal imagers, which is commonly referred to as thermovision measurement.Thermal imager is a tool that can be used for predictive maintenance activities to monitor the condition and performance of an equipment so that the possibility of equipment failure can be minimized. In October 2020, after thermovisiting transformer bay 6 at the Sunyaragi substation, it was discovered that there was a hotspot on the T-phase separation blade, causing heating of the blade, the above conditions can result in a decrease in PMS performance, with the worst condition if left alone can result in damage to the PMS blade and can also melt when the peak load is on the transformer 6. Under these conditions, maintenance is carried out by maintaining contact resistance, insulation resistance, and grounding resistance. The results of the analysis of contact resistance after maintenance show that the equipment is in good condition and still suitable for use, with a value of $7 \mu \Omega$ for the $R$ phase, $6.5 \mu \Omega$ for the $S$ phase, and $6.7 \mu \Omega$ for the T phase.
\end{abstract}

Keywords: PMS, Thermovisi, Thermal Imager

\section{Pendahuluan}

Energi listrik merupakan salah satu kebutuhan manusia yang penting dan tidak dapat dilepaskan dari keperluan sehari-hari. Di zaman modern, energi listrik sangat penting guna menunjang kegiatan dan aktifitas masyarakat serta industri. Energi listrik dengan kualitas dan kontinunitas yang baik didapat dengan cara melakukan pemeliharaan secara berkala guna menjaga kondisi setiap peralatan agar dapat mencegah gangguan yang dapat mengakibatkan kerusakan pada sistem [1].

energi yang diradiasikan oleh objek terhadap energi yang diradiasikan oleh benda hitam pada suhu dan gelombang yang sama.

Alat untuk melakukan pengamatan dan pencarian nilai emisivitas objek yaitu alat thermo imagers tipe SATIR D300. Dengan demikian dapat dideteksi peralatan yang ada di switchyard dalam keadaan baik atau rusak.

Pada bulan Oktober 2020 setelah melakukan thermovisi pada bay trafo 6 di gardu induk Sunyaragi diketahui terdapat hotspot pada bagian pisau PMS fasa $T$ sehingga menyebabkan pemanasan pada pisau tersebut.

Dengan kondisi tersebut di atas dapat mengakibatkan penurunan unjuk kerja PMS, dengan kondisi terburuk apabila di biarkan saja akan mengakibatkan kerusakan pada pisau PMS dan bisa juga meleleh jika saat beban puncak pada trafo 6 itu.

Oleh karena itu untuk memperbaiki temuan anomali hotspot di atas, pada Maret 2021 PT PLN (Persero) UPT Cirebon telah melaksanakan perbaikan temuan thermovisi pada pisau PMS fasa T bay Trafo 6 di GI Sunyaragi untuk mengatasi masalah hotspot tersebut.

Dari serangkaian kegiatan pemeliharaan didapatkan hasil tahanan kontak, (sesuai standar SK DIR. No :0520-2.K/DIR/2014), dan sudah tidak terdapat lagi hotspot. Sehingga disimpulkan bahwa PMS dalam kondisi baik dan aman untuk di operasikan. 


\section{Landasan Teori}

\subsection{Pengertian Thermovisi}

Pada pada setiap peralatan listrik pasti memiliki nilai konduktivitas yang tinggi, hal tersebut dikarenakan agar mampu menghantarkan listrik. dan sebagian besar peralatan litrik tersebut terbuat dari bahan logam, seperti tembaga, alumunium, dan lain sebagainya. Selain memiliki nilai konduktivitas yang tinggi, peralatan listrik pada umumnya juga memiliki nilai resistansi, sehingga apabila peralatan listrik tersebut dialiri oleh listrik atau dapat dikatakan dalam keadaan operasi maka dapat menghasilkan panas. Panas tersebut terjadi karena nilai resistansi yang dimiliki oleh peralatan. Bagian yang sering mengalami pemanasan dan harus sering diperhatikan adalah terminal dan sambungan (klem dengan konduktor) serta pada pisau atau kontak gerak pada peralatan seperti pada pemisah [2].

Sambungan konduktor menghasilkan tahanan sambungan (tahanan kontak). Sambungan yang memiliki tahanan kontak yang lebih besar dari tahan konduktor akan mengakibatkan panas yang lebih tinggi pada sambungan tersebut (hot point), sehingga semakin besar arus listrik yang mengalir maka semakin tinggi temperaturnya [3].

Pemeriksaan yang dilakukan secara operasi tersebut menggunakan Thermal Imager atau Thermovisi. Pengukuran ini menggunakan sinar infrared yang dipancarkan oleh thermal imagers sehingga pada display thermal imager dapat terlihat suhu dari peralatan yang diukur. dan apabila suatu peralatan yang telah dilakukan pengukuran thermovisi dengan menggunakan thermal imagers menunjukan hasil yang tidak baik (suhu peralatan yang terlalu tinggi), maka salah satu bentuk penyelesaian dari penangan kondisi tersebut sadalah dengan melakukan penguatan (pengencangan) klem dan konduktor, atau perbaikanperalatan listrik tersebut dan bahkan memungkinkan untuk dilakukan penggantian peralatan [4].
Prinsip kerja dari pengukuran ini yaitu, dengan mengukur nilai perbandingan energi yang diradiasikan oleh suatu objek (gelombang elektromagnet) terhadap energi yang diradiasikan oleh benda hitam pada suhu dan gelombang yang sama [4].

\subsection{Standard Thermovisi}

Pengukuran thermovisi dimuat dalam Buku Pedoman Pemeliharaan PLN No. 05202.K/DIR/2014, sebagai salah satu acuan prosedur pemeliharaan peralatan PLN yang terdapat di GI. Berdasarkan standar dari buku pedoman tersebut interpretasi hasil thermovisi dapat dikategorikan sebagai berikut:

Tabel 1. Standard thermovisi

\begin{tabular}{|l|l|l|}
\hline No. & $\begin{array}{l}\Delta \mathrm{T} \\
\text { (perbedaan } \\
\text { suhu antar } \\
\text { fasa) }\end{array}$ & Rekomendasi \\
\hline 1 & $1{ }^{\circ} \mathrm{C}-3^{\circ} \mathrm{C}$ & $\begin{array}{l}\text { Dimungkinkan ada } \\
\text { ketidaknormalan, perlu } \\
\text { investigasi lanjut }\end{array}$ \\
\hline 2 & $4{ }^{\circ} \mathrm{C}-15^{\circ} \mathrm{C}$ & $\begin{array}{l}\text { Mengindikasikan } \\
\text { adanya defesiensi, perlu } \\
\text { dijadwalkan perbaikan }\end{array}$ \\
\hline 3 & $>16^{\circ} \mathrm{C}$ & $\begin{array}{l}\text { Ketidaknormalan } \\
\text { Mayor, perlu dilakukan } \\
\text { perbaikan / penggantian } \\
\text { segera }\end{array}$ \\
\hline
\end{tabular}

Standar Pengukuran Thermovisi berdasarkan Buku Pedoman Pemeliharaan PLN No. 0520-

\section{K/DIR/2014}

Berdasarkan Tabel. 1, pelaksanaan pengukuran dilaksanakan minimal 1 bulan sekali. Untuk kondisi tertentu, periode pengukuran dapat dilakukan sesuai kebutuhan. Dan pada umumnya pengukuran thermovisi dilakukan per minggu

\subsection{Kamera Infrared (Thermal Imager)}

Thermal imager adalah salah satu alat yang dapat digunakan untuk kegiatan predictive maintenance untuk memonitor kondisi dan performance suatu peralatan sehingga kemungkinan terjadinya kegagalan peralatan dapat diperkecil. Teknologi 
thermography merupakan salah satu peralatan teknologi Non Destructive Testing NonContact atau NDT of Materials Evaluation. Seperti halnya thermometer, alat ini juga berfungsi untuk mengukur suhu suatu benda (peralatan listrik) tanpa menyentuh benda tersebut. Hal tersebut dapat terjadi karena alat tersebut memancarkan sinar infrared kemudian menangkap kembali radiasi dari objek yang diukur. Peralatan listrik yang diukur disini haruslah dalam keadaan operasi, karena saat elektron bergerak, memberikan kenaikan kepada kemampuan penghantaran arus listrik yang dapat menimbulkan panas terhadap apa yang dilewati elektron tersebut [3].

SATIR D300 dan D600 adalah kamera termografi multi aplikasi dengan fitur lengkap untuk inspeksi dalam dan luar ruangan. Alat ini dilengkapi dengan lensa tele yang berfungsi untuk zoom objek dan untuk menambah presisi pengukuran [5].

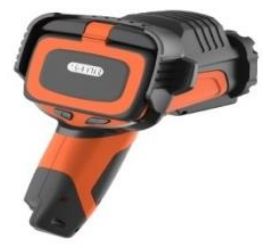

Gambar 1. Satir D300

\subsection{Pengertian PMS}

Pemisah (PMS) merupakan peralatan sistem tenaga listrik yang mempunyai fungsi bahwa saklar pemisah rangkaian listrik tidak ada arus beban (dipisahkan peralatan listrik dari peralatan lain yang mempunyai daya tegang). Hal inilah, pembuka dan penutup PMS digunakan secara langsung dengan kondisi tanpa beban. Disconnecting Switch mempunyai fungsi sebagai pemisah alat listrik dari alat lain ke instansi lain juga yang mempunyai arus tegangan. PMS juga dapet dibuka dan ditutup dengan kondisi bagianbagian yang tidak terbeban [6].

\subsection{Penempatan Posisi}

Sesuai dengan penempatannya di daerah mana Pemisah tersebut dipasang, PMS dapat dibagi menjadi:

1. Pemisah Penghantar/Line

Pemisah yang terpasang di sisi penghantar.

2. Pemisah Rel/ Bus

Pemisah yang terpasang di sisi Rel

3. Pemisah Kabel

Pemisah yang terpasang di sisi kabel

4. Pemisah Seksi

Pemisah yang terpasang pada suatu rel sehingga rel tersebut dapat terpisah menjadi dua seksi

5. Pemisah Tanah

Pemisah yang terpasang pada penghantar line / kabel untuk menghubungkan ke tanah [7].

\subsection{Pisau atau Kontak Pemisah}

Menghubungkan atau memisahkan bagian yang bertegangan. Macam-macam pisau pemisah berdasarkan gerakan lengan/pisau pemisahnya antara lain:

1. Pemisah engsel

Dimana pemisah tersebut gerakannya seperti engsel.

2. Pemisah putar

Dimana terdapat 2 (dua) buah kontak diam dan 2 (dua) buah kontak gerak yang dapat berputar pada sumbunya.

3. Pemisah siku

Pemisah ini tidak mempunyai kontak diam, hanya terdapat 2 (dua) kontak gerak yang gerakannya mempunyai sudut $90^{\circ}$.

4. Pemisah luncur

Pemisah ini Gerakan kontaknya keataskebawah (vertical) atau kesamping (horizontal), banyak di operasikan pada instalasi $20 \mathrm{kV}$.

5. Pemisah pantograph

PMS ini mempunyai kontak diam yang terletak pada rel dan kontak gerak yang terletak pada ujung lengan pantograph. Jenis ini banyak dioperasikan pada sistem tegangan $500 \mathrm{kV}$ [8].

\section{Metode Penelitian}

Dalam penulisan ini penulis melakukan penelitian di PT. PLN (Persero) UITJBT Unit Pelaksana Transmisi Cirebon Gardu Induk 
Sunyaragi, yang beralamat di Jl. Brigjen Dharsono (By Pass), Kec. Kesambi, Kota Cirebon Jawa Barat 45131.

Pada penyelesaian ini ada beberapa langkah kerja yang dilakukan antara lain:

1. Studi literatur, dalam studi literatur dilakukan pencarian informasi baik dari buku, jurnal, bahan dari internet maupun sumber-sumber lain seperti Foto hasil thermovisi pada pemisah rel trafo 6 GI Sunyaragi, Single line GI Sunyaragi.

2. Pengambilan data, Pada penelitian ini, data yang diambil dan di analisa adalah data hasil pengujian saat pemelihara tahunan, setelah dilaksanakan perb 49 dan sebelum dilaksanakan perbaikan, hasil thermovisi selama tahun 2020.

3. Analisa, Pada tahap ini dilakukan analisa hasil dari data yang sudah didapat, apakah peralatan tersebut masih layak operasi sesuai standar yang ditentukan atau perlu penggantian.

Pengukuran suhu dengan thermography akan selalu memberikan nilai absolut dari objek terukur. Untuk menentukan dengan benar apakah suhu objek terlalu panas (overheating).

\section{Hasil dan Pembahasan}

\subsection{Inspeksi Visual}

Inspeksi visual merupakan inspeksi yang dilakukan dengan menggunakan panca indera dengan pelaksanaan periode tertentu dalam keadaan peralatan bertegangan. Inspeksi / pengecekan bertujuan untuk memonitor kondisi komponen peralatan.

\subsection{In Service Measurement}

In service measurement merupakan pengukuran yang dilakukan dengan alat ukur yang yaitu thermovision Thermal Imager dengan pelaksaan periode bulanan yang dilakukan oleh petugas pemeliharaan Supervisor Gardu Induk dalam keadaan peralatan bertegangan.

\subsection{Hasil Thermovisi Sebelum Perbaikan}

Hasil thermovisi sebelum perbaikan dari PMS rel 2 bay trafo 6 pukul 19.00 WIB, fasa R dapat dilihat pada Gambar 2, fasa S Gambar 3, fasa T Gambar 4

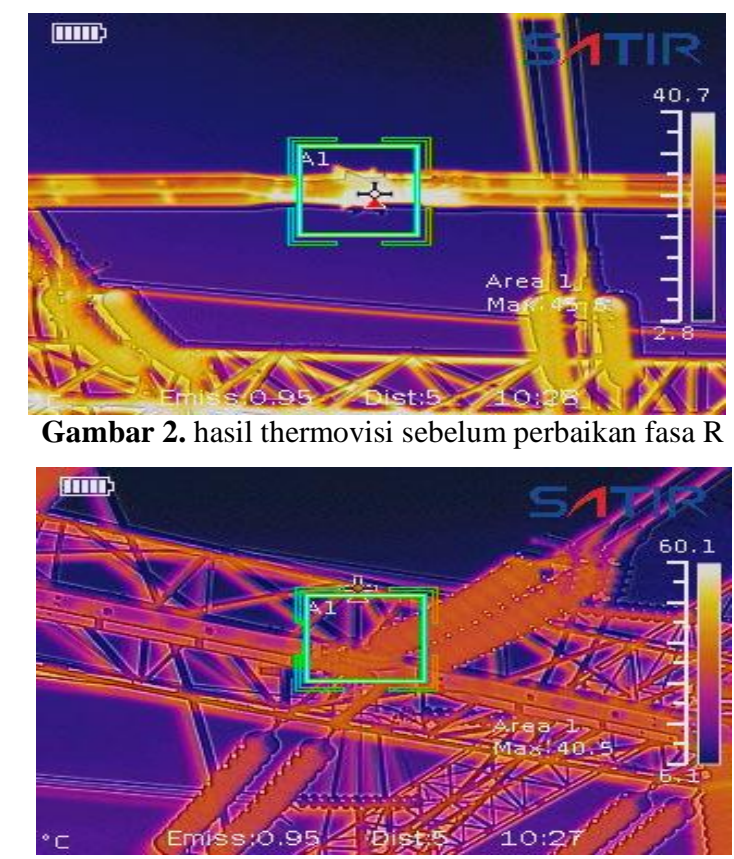

Gambar 3. hasil thermovisi sebelum perbaikan fasa S

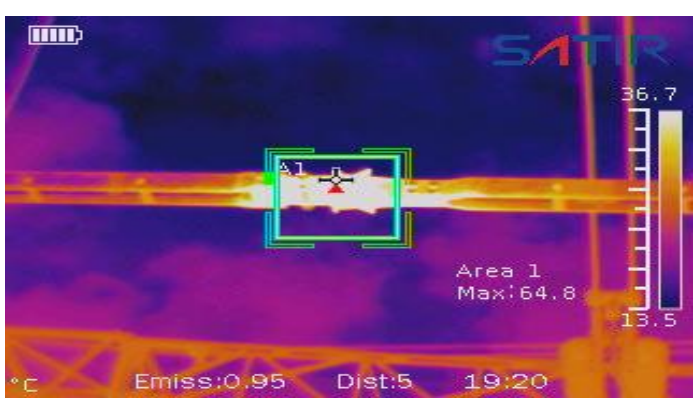

Gambar 4. hasil thermovisi sebelum perbaikan fasa $\mathrm{T}$

\begin{tabular}{|c|c|c|c|c|c|c|c|}
\hline \multicolumn{9}{|c|}{ Nilai Tkur Themovisi } \\
\hline \multicolumn{3}{|c|}{ Pukul 10.00 WIB } & \multicolumn{5}{c|}{ Pukul 19.00 WIB } \\
\hline Fasa R & Fasa S & Fasa T & Konduktor & Fasa R & Fasa S & Fasa T & Konduktor \\
\hline 54,4 & 40,5 & 69,0 & 41,2 & 45,8 & 40,5 & 64,8 & 28,2 \\
\hline \multicolumn{3}{|c|}{ Perbaikan segera } & \multicolumn{4}{|c|}{ Perbaikan segera } & \\
\hline
\end{tabular}

Berdasarkan Tabel 2, untuk hasil pengukuran thermovisi sebelum perbaikan, pukul 10.00 WIB menunjukan hasil rekomendasi perbaikan segera dengan batas selisih suhu antar fasa yang menujukan nilai yaitu 28,5. dan pada pukul 19.00 WIB menunjukan hasil rekomendasi perbaikan segera dengan batas selisih suhu antar fasa yang menujukan nilai yaitu 35,6 . 


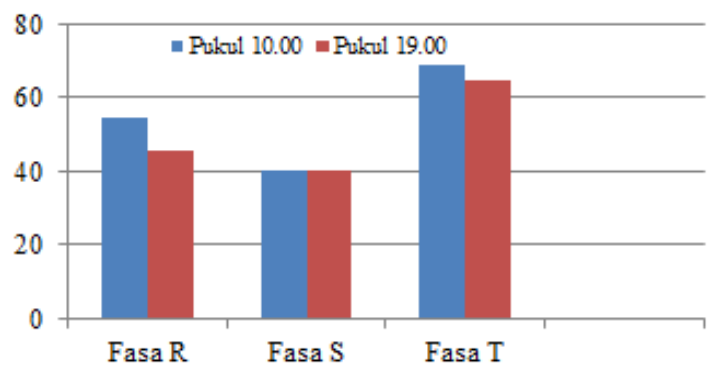

Gambar 5. Grafik hasil thermovisi sebelum perbaikan

Dilihat dari Grafik pada Gambar 5, menunjukan hasil pengukuran thermovisi sebelum perbaikan, pada fasa $\mathrm{T}$ diperoleh hasil lebih tinggi dibandingkan dengan fasa $\mathrm{R}$ ' fasa $\mathrm{S}$, baik pada pukul 10.00 WIB mal 50 pada pukul 19.00 WIB. Hal ini menunjı bahwa pada fasa $\mathrm{T}$ terjadi hostpot atau dalam kondisi anomali.

\subsection{Hasil Thermovisi Setelah Perbaikan}

Hasil thermovisi setelah perbaikan dari PMS rel 2 bay trafo 6 , fasa $\mathrm{R}$ dapat dilihat pada Gambar 6, fasa $S$ Gambar 7, fasa $T$ Gambar 8.

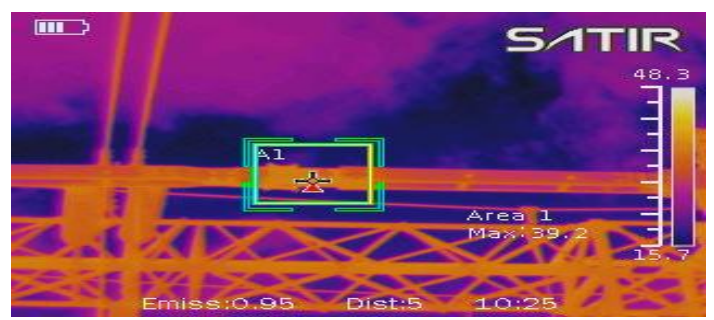

Gambar 6. hasil thermovisi setelah perbaikan Fasa R

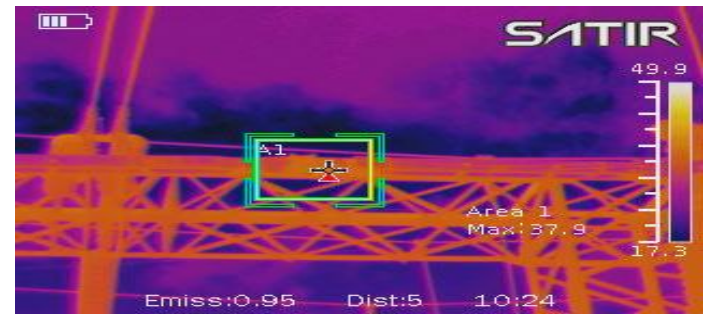

Gambar 7. hasil thermovisi setelah perbaikan Fasa S

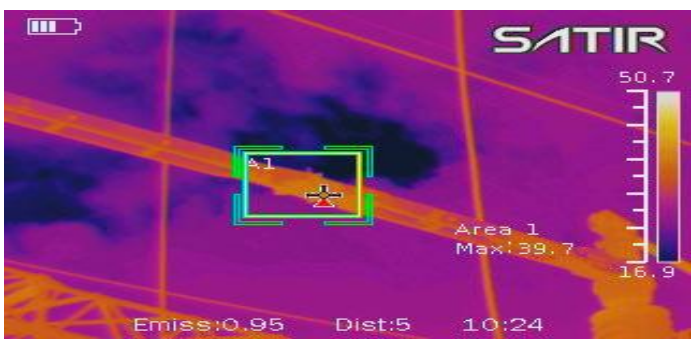

Gambar 8. hasil thermovisi setelah perbaikan Fasa T

Tabel 3. Hasil ukur Thermovisi Setelah perbaikan

\begin{tabular}{|c|c|c|c|}
\hline \multicolumn{4}{|c|}{ Nilai Ukur Thermovisi } \\
\hline Fasa R & Fasa S & Fasa T & Konduktor \\
\hline 39,2 & 37,9 & 39,7 & 37,6 \\
\hline \multicolumn{3}{|c|}{ Kondisi baik } & \\
\hline
\end{tabular}

Berdasarkan Tabel 3, hasil pengukuran thermovisi setelah perbaikan, baik pada Fasa $\mathrm{R}, \mathrm{S}$, dan T menunjukan kondisi baik. Hal ini dibuktikan bahwa hasil pengukuran tersebut sudah sesuai standar PLN yaitu $<40^{\circ} \mathrm{C}$.

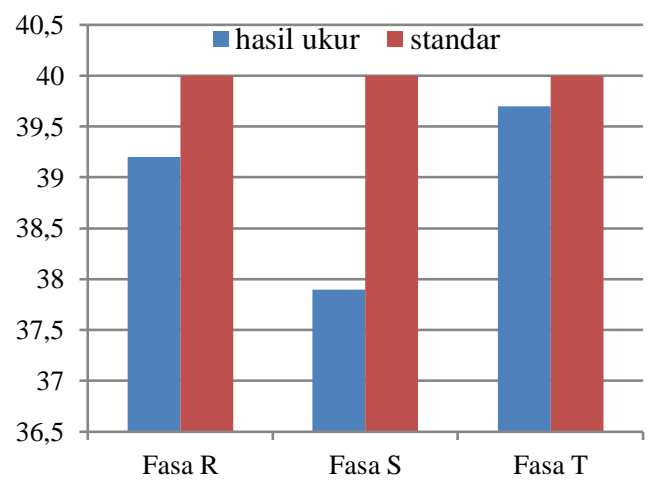

Gambar 9. Grafik hasil thermovisi setelah perbaikan

Dilihat dari Grafik pada Gambar 9, menunjukan hasil pengukuran thermovisi setelah perbaikan, pada Fasa $\mathrm{R}, \mathrm{S}$, dan $\mathrm{T}$ menunjukan nilai masing-masing yaitu 39,2, 37,9 dan 39,7. Hal ini menunjukan bahwa pada Fasa R, S, dan T dalam keadaan normal. Semakin rendah hasil pengukuran thermovisi maka semakin baik pula keadaan peralatan tersebut.

\subsection{Shutdown Measurement}

Shutdown measurement merupakan pengukuran yang dilakukan dengan alat ukur dengan periode 2 tahunan. Umumnya peralatan PMS yang baru selesai pemasangan sebelum dioperasikan maupun yang sudah jatuh tempo pemeliharaan, perlu dilakukan pengujian-pengujian untuk mendapatkan unjuk kerja dari peralatan tersebut, dalam keadaan peralatan tidak beroperasi.Selama 
pengujian posisi switch harus dalam posisi local dan mini circuit breaker (MCB) motor dalam posisi off.

\subsection{Hasil Pengukuran Tahanan Isolasi}

Berikut hasil pengukuran tahanan isolasi Pemisah (PMS) Sebelum dan Sesudah perbaikan bay trafo 6 150/20 kV Sunyaragi :

Tabel 4. Hasil ukur tahanan isolasi

\begin{tabular}{|c|c|c|c|c|c|c|c|c|c|}
\hline \multirow{2}{*}{$\begin{array}{l}\text { Titili } \\
\text { Ukur }\end{array}$} & \multicolumn{3}{|c|}{ Fass R } & \multicolumn{3}{|c|}{$\begin{array}{l}\text { Fass S } \\
\text { nass }\end{array}$} & \multicolumn{3}{|c|}{ Fass T } \\
\hline & Standard & $\begin{array}{l}\text { Thann } \\
\text { lalu }\end{array}$ & $\begin{array}{l}\text { Hasil } \\
\text { ukur }\end{array}$ & Standard & $\begin{array}{l}\text { Tahun } \\
\text { lalu }\end{array}$ & $\begin{array}{l}\text { Hasil } \\
\text { ukur }\end{array}$ & Standard & $\begin{array}{l}\text { Tahun } \\
\text { lalu }\end{array}$ & $\begin{array}{l}\text { Hasil } \\
\text { ukur }\end{array}$ \\
\hline $\begin{array}{l}\text { Atas. } \\
\text { ground }\end{array}$ & 11kVIMI & $\$ 1000 \mathrm{G}$ & S1000G & $1 \mathrm{l} \mathrm{V} / \mathrm{M} \Omega$ & $\$ 1000 \mathrm{G}$ & $31000 \mathrm{G}$ & $1 \mathrm{kV} / \mathrm{M} \Omega$ & $\$ 1000 G$ & $\$ 1000 G$ \\
\hline
\end{tabular}

keadaan cukup baik dan memenuhi standard karena hasil pengukuran menunjukan $>1 \mathrm{kV} / 1 \mathrm{M} \Omega$. Sedangkan dari tabel hasil pengukuran tahanan isolasi setelah perb $c 51$ dapat dikatakan dalam keadaan cukup baik memenuhi standard karena hasil pengukuran menunjukan $>1 \mathrm{kV} / 1 \mathrm{M} \Omega$.

\subsection{Hasil Pengukuran Tahanan Kontak}

Alat ukur tahanan kontak merek programma terdiri dari sumber arus dan alat ukur tegangan (drop tegangan pada objek yang diukur) dengan sistem elektronik maka pembacaan dapat diketahui dengan baik dan ketelitian yang cukup baik pula (digital).

Rangkaian tenaga listrik sebagian besar terdiri dari banyak titik sambungan.Sambunganadalah dua atau lebih permukaan dari beberapa jenis konduktor bertemu secara fisiksehingga arus/energi listrik dapat disalurkan tanpa hambatan yang berarti.Pertemuan dari beberapa konduktor menyebabkan suatu hambatan/resistan terhadaparus yang melaluinya sehingga akan terjadi panas dan menjadikan kerugian teknis. Rugi ini sangat signifikan jika nilai tahanan kontaknya tinggi.

Tabel 5. Hasil ukur tahanan kontak

\begin{tabular}{|c|c|c|c|c|c|c|c|c|c|}
\hline $\begin{array}{c}\text { Titik } \\
\text { Ukur }\end{array}$ & \multicolumn{3}{|c|}{ Fasa R } & \multicolumn{3}{c|}{ Fass $S$} & \multicolumn{3}{c|}{ Fasa I } \\
\hline & Standard & Sebelum & Sesudah & Standard & Sebelum & Sesudah & Standard & Sebelum & Sesudah \\
\hline $\begin{array}{c}\text { Pisaul- } \\
\text { Pisau }\end{array}$ & $<10 \mu \Omega$ & $50.1 \mu$ & $7 \mu \Omega$ & $<10 \mu \Omega$ & $25 \mu \Omega$ & $6.5 \mu \Omega$ & $<10 \mu \Omega$ & $80 \mu \Omega$ & $6.7 \mu \Omega$ \\
\hline Total & $<100 \mu \Omega$ & $200 \mu \Omega$ & $119 \mu \Omega$ & $<100 \mu \Omega$ & $150 \Omega$ & $118 \mu \Omega$ & $<100 \mu \Omega$ & $250 \mu \Omega$ & $112 \mu \Omega$ \\
\hline
\end{tabular}

Dilihat dari Tabel 5, dapat dinyatakan bahwa fasa $\mathrm{R}, \mathrm{S}$, dan $\mathrm{T}$ pada saat sebelum perbaikan tahanan kontak pisau-pisau menunjukan nilai diatas standard PLN yaitu < $10 \mu \Omega$, serta untuk nilai tahanan kontak PMS secara total juga menunjukan nilai diatas standard PLN yaitu $<100 \mu \Omega$.

Dan dari Tabel 5, dapat dinyatakan bahwa fasa $\mathrm{R}, \mathrm{S}$, dan $\mathrm{T}$ pada saat setelah perbaikan tahanan kontak pisau-pisau menunjukan nilai standard PLN yaitu $<10 \mu \Omega$, serta untuk nilai tahanan kontak pemisah secara total juga menunjukan nilai standard PLN yaitu $<100$ $\mu \Omega$.

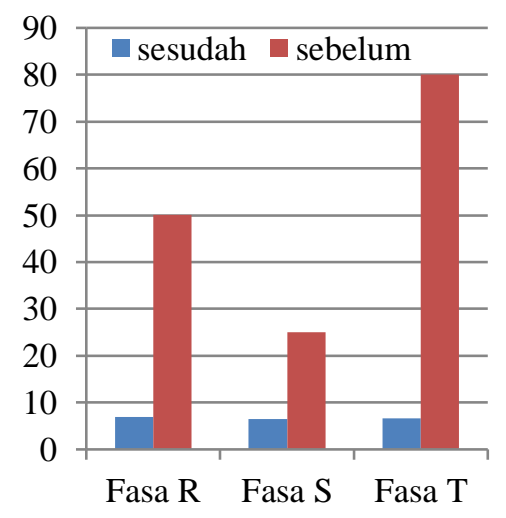

Gambar 10. Grafik hasil pengukuran tahanan kontak titik ukur pisau-pisau

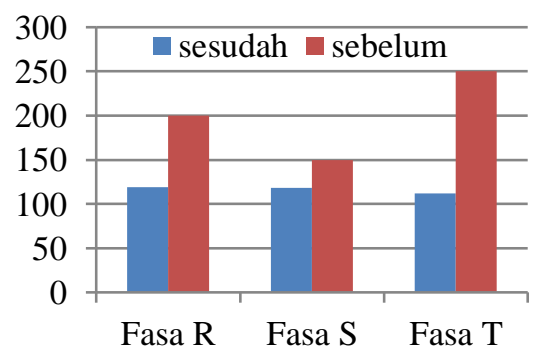

Gambar 11. Grafik hasil pengukuran tahanan kontak titik ukur total

\subsection{Hasil Pengukuran Pentanahan}

Pengukuran tahanan pentanahan bertujuan untuk menentukan tahanan antara besi atau plat tembaga yang ditanam dalam tanah yang digunakan untuk melindungi peralatan listrik 
terhadap gangguan petir dan hubung singkat. Dengan demikian pelat tersebut harus ditanam hingga mendapatkan tahanan terhadap tanah yang sekecil-kecilnya. Untuk mengukur tahanan pentanahan digunakan alat ukur tahanan pentanahan (Earth Resistance Tester).

Tabel 6. Hasil ukur pentanahan

\begin{tabular}{|c|c|c|}
\hline \multicolumn{2}{|c|}{ Titik Ukur } & $\begin{array}{c}\text { Pentanahan grounding } \\
\text { PMS }\end{array}$ \\
\hline \multirow{3}{*}{$\begin{array}{c}\text { Fasa } \\
\mathrm{R}\end{array}$} & Standard & $<1 \Omega$ \\
\hline & $\begin{array}{c}\text { Tahun } \\
\text { lalu }\end{array}$ & $0.17 \Omega$ \\
\hline & $\begin{array}{l}\text { Hasil } \\
\text { ukur }\end{array}$ & $0.17 \Omega$ \\
\hline \multirow{3}{*}{$\begin{array}{c}\text { Fasa } \\
\mathrm{S}\end{array}$} & Standard & $<1 \Omega$ \\
\hline & $\begin{array}{c}\text { Tahun } \\
\text { lalu }\end{array}$ & $0.17 \Omega$ \\
\hline & $\begin{array}{c}\text { Hasil } \\
\text { ukur }\end{array}$ & $0.17 \Omega$ \\
\hline \multirow{3}{*}{$\begin{array}{c}\text { Fasa } \\
\mathrm{T}\end{array}$} & Standard & $<1 \Omega$ \\
\hline & $\begin{array}{c}\text { Tahun } \\
\text { lalu }\end{array}$ & $0.17 \Omega$ \\
\hline & $\begin{array}{l}\text { Hasil } \\
\text { ukur }\end{array}$ & $0.17 \Omega$ \\
\hline
\end{tabular}

Dilihat dari Tabel 6, dapat dinyatakan bahwa pengukuran pentanahan pada grounding PMS baik Fasa $R, \quad S$, dan $T$ tidak terdapatperubahan dan sesuai dengan standar PLN yaitu $<1 \Omega$.

\section{Kesimpulan}

1. Dilihat dari serangkaian, menyatakan bahwa hasil uji PMS rel 2 bay Trafo 6 GI Sunyaragi masih dalam keadaan baik dan aman untuk di operasikan.

2. Pemeliharaan PMS meliputi:

a. Dari hasil pelaksanaan inpeksi visual menggunakan panca indera yaitu secara visual dan pendengaran, peralatan masih dalam kondisi normal dan aman beroperasi.

b. Dari hasil pengukuran thermovisi PMS sebelum dan sesudah perbaikan didapat hasil sebagai berikut:

1) Pada fasa $R$ suhu awal menunjukan angka $54,4^{\circ} \mathrm{C}$ dan setelah diperbaiki menunjukan suhu normal yaitu $39,2^{\circ} \mathrm{C}$.
2) Pada fasa $S$ suhu awal menunjukan angka $40,5^{\circ} \mathrm{C}$ dan setelah diperbaiki menunjukan suhu normal yaitu $37,9^{\circ} \mathrm{C}$.

3) Pada fasa $R$ suhu awal menunjukan angka $69^{\circ} \mathrm{C}$ dan setelah diperbaiki menunjukan suhu normal yaitu $39,7^{\circ} \mathrm{C}$.

c. Dari hasil pengukuran tahanan isolasi, dapat dikatakan dalam keadaan cukup baik karena hasilnya masih sesuai standard PLN yakni $>1000 \mathrm{G} \Omega$.

Dari hasil pengujian tahanan kontak, dapat dilihat bahwa hasil pengujian mengalami penurunan nilai tahanan kontak dari $50,1 \mu \Omega$ menjadi $7 \mu \Omega$ untuk fasa $\mathrm{R}$, dari $25 \mu \Omega$ menjadi $6,5 \mu \Omega$ untuk fasa $S$, dan dari $80 \mu \Omega$ menjadi $6,7 \mu \Omega$ untuk fasa $T$.

\section{DAFTAR PUSTAKA}

[1]. Anwar, Baharuddin, "Penentuan Hot point menggunakan metode thermovisi pada Gardu induk 150kV Purwodadi", Fakultas Teknik, University Muhammadiyah Surakarta, 2019.

[2]. Hariyadi, Shahlan, "Analisis Rugi-Rugi Dan Jatuh Tegangan Pada Saluran Transmisi Tegangan Tinggi $150 \mathrm{kV}$ Pada Gardu Induk Palur-Masaran”. Universitas Muhammadiyah Surakarta, 2017.

[3]. Ramadhani, Roni Putra, "Thermovisi dalam melihat Hot Point pada Gardu Induk $150 k v$ palur", Universitas Muhammadiyah Surakarta, 2018.

[4]. Fazawi, Muhammad Lutfhi, "Analisa penentuan hot poin dan monitoring peralatan dengan metode thermovisi pada GI $150 \mathrm{kV}$ Glugur", Medan, Universitas Muhammadiyah Sumatera Utara, 2020.

[5]. PT.PLN (Persero), "Instruksi Kerja Inspeksi Jaringan Transmisi dan Gardu Induk menggunakan kamera Thermovisi SATIR D Series", PT.PLN (Persero) Transmisi Jawa Bagian Tengah, 2018. 
[6]. Siregar, M. Sutan Iqbal, "Penggantian rele differensial mekanik ke rele differensial numerik", Jakarta, Institut Teknologi-PLN, 2020.

[7]. PT.PLN (Persero), “Buku Petunjuk Gardu Induk, SE No.0520-2.K/DIR/2014", Jakarta, PT. PLN (Persero), 2014.

[8]. PT.PLN (Persero), "Buku Pedoman Pemeliharaan Pemisah (PMS), SE No.0520-2.K/DIR/2014", Jakarta, PT. PLN (Persero), 2014. 